\title{
Metal-Free Nitrogen-Doped Carbon Foam Electrocatalysts for the Oxygen Reduction Reaction in Acid Solution
}

\author{
J. Liu, ${ }^{\text {a,b }}$ S. Yu, ${ }^{\text {c }}$ T. Daio, ${ }^{a, d}$ M. S. Ismail, ${ }^{e}$ K. Sasaki, ${ }^{a, c, d, f}$ and S. M. Lyth ${ }^{e, f, *, z}$ \\ ${ }^{a}$ Faculty of Engineering, Kyushu University, Fukuoka 819-0395, Japan \\ ${ }^{b}$ College of Energy and Mechanical Engineering, Shanghai University of Electric Power, Shanghai 200090, \\ People's Republic of China \\ ${ }^{c}$ International Research Center for Hydrogen Energy, Japan \\ ${ }^{d}$ Next-Generation Fuel Cell Research Center (NEXT-FC) \\ ${ }^{e}$ Department of Mechanical Engineering, University of Sheffield, South Yorkshire S3 7RD, United Kingdom

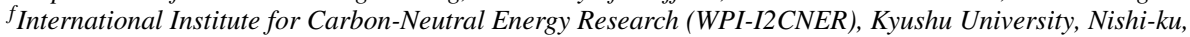 \\ Fukuoka, Japan
}

\begin{abstract}
Metal-free, nitrogen-doped carbon foam is utilized as a model non-precious electrocatalyst system to investigate the role of nitrogen in the oxygen reduction reaction (ORR) in the absence of iron contamination. This graphene-like foam displays relatively high activity for the ORR in acid, despite being proven free from transition-metal impurities. The onset potential is $0.85 \mathrm{~V}_{\mathrm{RHE}}$, the mass activity is $2.8 \mathrm{~A} / \mathrm{g}$ at $0.6 \mathrm{~V}_{\mathrm{RHE}}$, and the current density is $-4.0 \mathrm{~mA} / \mathrm{cm}^{2}$. The maximum electron transfer number is calculated to be 3.6 , revealing that a 4-electron pathway is possible in nitrogen-doped carbon, even in the absence of transition-metal coordination sites. The excellent electrochemical activity is attributed to the large surface area $\left(700 \mathrm{~m}^{2} / \mathrm{g}\right)$, improved conductivity after graphitization, and the relatively high proportion of tertiary (graphite-like) nitrogen.

(C) The Author(s) 2016. Published by ECS. This is an open access article distributed under the terms of the Creative Commons Attribution 4.0 License (CC BY, http://creativecommons.org/licenses/by/4.0/), which permits unrestricted reuse of the work in any medium, provided the original work is properly cited. [DOI: 10.1149/2.0631609jes] All rights reserved.
\end{abstract}

Manuscript submitted May 20, 2016; revised manuscript received June 29, 2016. Published July 12, 2016.

Non-platinum group metal (non-PGM) electrocatalysts for the oxygen reduction reaction (ORR) are desired in order to reduce the cost and improve the durability of proton exchange membrane fuel cells (PEMFCs). Transition metal-based electrocatalysts have long been suggested as alternative electrocatalysts. Starting in the 1970's, early attempts were made to utilize transition metal-containing macrocyclic complexes as biomimetric ORR electrocatalysts, taking inspiration from their usefulness in nature. ${ }^{1}$ However, soon it was discovered that heat-treatment of these macrocycles resulted in better activity and durability, ${ }^{2}$ leading to debate over the precise chemical composition of the active site. Later still, it was realized that the macrocyclic complex was not necessary at all, but that seemingly arbitrary mixtures of Fe (or $\mathrm{Co})$, nitrogen and carbon could lead to very active electrocatalysts. ${ }^{3}$ Since then, a vast amount of research output has been produced from a number of groups across the world. ${ }^{4-8}$ In recent years, such electrocatalysts have become a mainstream research topic, with the DOE setting specific targets for a non-PGM cathode in a $\mathrm{H}_{2} /$ air PEMFC; namely a volumetric activity of $300 \mathrm{~A} / \mathrm{cm}^{3}$ measured at $800 \mathrm{mV}_{\text {iR-free }}$ by $2017 .{ }^{9}$ These targets have been all but met, ${ }^{10}$ and non-PGM electrocatalysts are now commercially available.

The issue of the nature of the active site has never gone away, and is still frequently debated. ${ }^{11}$ Complicating the issue is the fact that the ORR can proceed via either a 4- or 2-electron pathway to produce water or hydrogen peroxide (which can then further decompose to water), respectively. The 4-electron pathway is most desired in fuel cells, but the 2-electron pathway is significantly present in most non-precious electrocatalysts. The consensus in recent years has drifted toward the active site being comprised of pyridinic nitrogen atoms near a defect or edge, coordinated with a transition metal atom, with strong evidence of this provided by Mossbauer spectroscopy. ${ }^{12}$ The clustering of nitrogen atoms in this manner has been observed in graphene in high resolution scanning tunneling microscopy (STM) measurements, and is possible because this is a low energy atomic configuration. ${ }^{13}$ However, other models have been proposed describing a metal-free active site, ${ }^{14-17}$ in which, for example, tertiary bonded electronegative nitrogen atoms (near edges or defects) withdraw electrons from neighboring edge carbon atoms, increasing their positive charge. ${ }^{18-21}$ This increases the binding energy with incoming oxygen molecules.

*Electrochemical Society Member.

zE-mail: lyth@i2cner.kyushu-u.ac.jp
A third situation is also likely, in which a plurality of different configurations of ORR active sites for the ORR exist, and that both of the above proposed models are active.

Here, we focus on the second mechanism, which has received much less experimental attention in the literature. It must here be noted that metal-free electrocatalysts have been widely studied as ORR electrocatalysts in alkaline media where the cathode kinetics are much faster and non-PGM electrocatalysts can compete easily with Pt. ${ }^{15,22-25}$ However, this research is only relevant to alkaline fuel cells (AFCs), which are promising, but much further behind in commercial development than PEMFCs. The study of metal-free nitrogen-doped carbon electrocatalysts in acid media may have been neglected due to the much lower and therefore less "exciting" electrochemical activities that can be expected compared to their transition-metal-containing counterparts, or by measuring in alkaline medium. An additional issue is the difficulty in ensuring that samples are truly metal-free. Common carbon-based materials used in such research are carbon nanotubes or carbon black, both of which contain significant amounts of transition metal contamination. ${ }^{26,27}$ This fact is often not sufficiently discussed in such "metal-free" studies.

In 2009 , our group synthesized carbon nitride $\left(\mathrm{g}-\mathrm{C}_{3} \mathrm{~N}_{4}\right)$ as the ultimate metal-free nitrogen-doped carbon, and measured the ORR activity in acid medium. ${ }^{28}$ Although the activity was greater than that of carbon black, the current density was relatively bad due to the low surface area $\left(<10 \mathrm{~m}^{2} / \mathrm{g}\right)$, and poor electronic conductivity. We successfully increased the current density by supporting carbon nitride on carbon black, ${ }^{29}$ or carbon nanotubes, ${ }^{28}$ and by heat-treatment. However, metal contamination was a constant issue and could not be discounted. To avoid the presence of transition metals, our group began synthesis of nitrogen-doped graphene foam via thermal decomposition of sodium alkoxides and subsequent heat-treatment. ${ }^{30,31}$ Due to the high surface area and unique structure of these electrocatalysts, the ORR currents achieved were much higher than those previously obtained. Due to the purity of the precursors, and the synthesis in Teflon vessels, such samples are proven to be free of metal contamination.

Despite the difficulties involved, several other groups have made attempts to study metal-free nitrogen-doped carbon materials for the ORR in acid. For example, Sugimoto et al. studied pyrolyzed silk, and reported surface areas of $1018 \mathrm{~m}^{2} / \mathrm{g}$, onset potentials of $0.83 \mathrm{~V}_{\mathrm{RHE}}$, and current densities of $-5 \mathrm{~mA} / \mathrm{cm}^{2} .32,33$ They concluded that the large mesopore volume and surface area contributed significantly to the high 
activity, whilst tertiary (graphite-like) nitrogen plays an important role in 4-electron ORR. Chokai et al. prepared metal-free electrocatalysts with large surface area $\left(258 \mathrm{~m}^{2} / \mathrm{g}\right)$ by pyrolysis of polyimide, with onset potentials of $0.8 \mathrm{~V}_{\mathrm{RHE}} \cdot{ }^{34} \mathrm{Rao}$ et al. synthesized nitrogen-doped carbons with unspecified surface area utilizing sacrificial alumina templates. The best sample had 8.4 at $\%$ nitrogen, displayed an onset potential of $0.455 \mathrm{~V}_{\mathrm{Ag} / \mathrm{AgCl}}\left(\sim 0.67 \mathrm{~V}_{\mathrm{RHE}}\right)$, and a current density of -0.53 $\mathrm{mA} / \mathrm{cm}^{2}$. The catalytic activity was attributed to pyridinic nitrogen. ${ }^{35}$ Yu et al. synthesized metal-free nitrogen-doped single wall carbon nanotubes (with 3.6 at\% nitrogen) via a plasma etching process and achieved an onset potential of $0.5 \mathrm{~V}_{\mathrm{Ag} / \mathrm{AgCl}}\left(\sim 0.71 \mathrm{~V}_{\mathrm{RHE}}\right)$ and a current density of $-2 \mathrm{~mA} / \mathrm{cm}^{2}$, also attributed to pyridinic-type nitrogen. ${ }^{24} \mathrm{Fi}$ nally, Wang et al. synthesized ammonia-treated mesoporous carbons achieving a surface area of $1923 \mathrm{~m}^{2} / \mathrm{g}$, a nitrogen content of 4.6 at $\%$, an onset potential of $0.72 \mathrm{~V}_{\mathrm{NHE}}$ (i.e. $\sim 0.72 \mathrm{~V}_{\mathrm{RHE}}$ ), and a current density of $-4.2 \mathrm{~mA} / \mathrm{cm}^{2}{ }^{36}$ These are probably the best values published for a metal-free electrocatalyst in acid media to date. Some other groups have reported "metal-free" ORR electrocatalysts, but admit to up to $0.5 \mathrm{wt} \%$ iron contamination. ${ }^{22,37,38}$ The history and recent advances in $\mathrm{Fe} / \mathrm{N} / \mathrm{C}$ and their metal-free counterpart electrocatalysts have been presented in great detail in several recent reviews. ${ }^{11,39,40}$

Here, we expand on our previous research by performing high temperature graphitization of optimized nitrogen-doped carbon foam samples, and exploring how this affects the electrochemical activity.

\section{Experimental}

Synthesis of nitrogen-doped carbon foam.-Chemicals were used as received without further purification. Nitrogen-doped carbon foam was synthesized via combustion of nitrogen-containing sodium alkoxide. Anhydrous ethanol (Japanese pharmacopeia grade, Wako, $>99.5 \%$ ) and diethanolamine (Japanese Industrial Standards (JIS) special grade, Wako, $>99 \%$ ) were both added to a Teflon reactor, followed by an equimolar amount of sodium (Sigma-Aldrich, >99\%). The reactor was sealed, heated to $150^{\circ} \mathrm{C}$, and stirred magnetically overnight, before being cooled to room temperature. The resulting alkoxide powder was ignited, burning with a steady flame to form a black powder. This was crushed, sonicated, and washed in deionized water to remove residual sodium oxides, and then dried under vacuum.

The first sample was heat treated at $1000^{\circ} \mathrm{C}$ for 2 hours under nitrogen flow, and the again washed in deionized water. A second calcination step was performed at $800^{\circ} \mathrm{C}$ for 2 hours under $5 \mathrm{sccm} \mathrm{H}_{2}$ and $95 \mathrm{sccm} \mathrm{N}_{2}$ gas flow. This sample is herein referred to as $\mathrm{CN}_{\mathrm{x}}$ $1000 .^{31}$ The second sample was subjected to the same process, and then graphitized at $1400^{\circ} \mathrm{C}$ under $\mathrm{N}_{2}$ flow for 15 hours. This sample is herein referred to as $\mathrm{CN}_{\mathrm{x}}-1400$. Great care was taken throughout to avoid contact with any transition metal species through either cross contamination, or even by contact with stainless steel instuments. Despite this, some trace impurities may present in the reactants, especially in the sodium metal.

Materials characterization.-Samples were characterized by scanning electron microscopy (SEM, S-5200, Hitachi, Japan); transmission electron microscopy (TEM, HD-2300, Hitachi, Japan); BET surface area analysis (Belsorp mini II-VS, Bel Japan, Inc.); X-ray photoelectron spectroscopy (XPS, ESCA-3400, Kratos Analytical Ltd., $\mathrm{UK}$ ); and inductively coupled plasma - atomic emission spectrometry (ICP-AES, Shimadzu Corp., ICPE-9000).

Electrode preparation.-Working electrodes were prepared according to the methods recommended by the Fuel Cell Commercialization Conference of Japan (FCCJ). Electrocatalysts were dispersed in a mixture of deionized water, ethanol (Wako) and $5 \mathrm{wt} \%$ Nafion solution (Wako) in a volume ratio of 3:3:1, then sonicated for $30 \mathrm{~min}$. A glassy carbon-disk platinum-ring electrode $\left(0.196 \mathrm{~cm}^{2}\right.$, Hokuto Denko Corp.) was coated with $8 \mu \mathrm{L}$ of catalyst ink, then dried at $60^{\circ} \mathrm{C}$ for $15 \mathrm{~min}$. The resulting density of the electrocatalyst material on the glassy carbon electrode was $0.58 \mathrm{mgcm}^{-2}$.
Cyclic voltammetry $(\mathrm{CV})$ and linear sweep voltammetry (LSV).Electrochemical measurements were performed using a typical rotating ring-disk electrode (RRDE) system (HX-107, Hokuto Denko Corp., Japan), in $\mathrm{N}_{2}$-saturated $0.1 \mathrm{M}$ perchloric acid (Aldrich). All potentials were calculated relative to the reversible hydrogen electrode (RHE). The working electrode was a glassy-carbon-disk platinum-ring electrode, the counter electrode was a platinum wire, and $\mathrm{Ag} / \mathrm{AgCl}$ was used as the reference electrode. Cyclic voltammograms (CV) were obtained in the range 0.05 to $1.2 \mathrm{~V}_{\mathrm{RHE}}$, with a scan rate of $50 \mathrm{mVs}^{-1}$ in $\mathrm{N}_{2}$-saturated solution. Linear sweep voltammograms (LSV) were performed in the range 0.2 to $1.2 \mathrm{~V}_{\mathrm{RHE}}$, with a scan rate of $10 \mathrm{mVs}^{-1}$ in $\mathrm{O}_{2}$ saturated electrolyte at $400,900,1600$, and 2500 rpm. Onset potentials were determined using $1^{\text {st }}$ derivative plots. The kinetically controlled current, $i_{\mathrm{k}}$, is determined from the intercept of Koutecky-Levich plots. The mass activity at $0.60 \mathrm{~V}_{\mathrm{RHE}}$ is based on ORR measurements at different rotating speeds. In general the mass activity is measured at $0.9 \mathrm{~V}_{\mathrm{RHE}}$, but since this would be zero in the case of most metal-free catalysts, $0.60 \mathrm{~V}_{\mathrm{RHE}}$ is used for comparison of these samples. The electron transfer number $(\mathrm{N})$ was obtained from the ring current $\left(\mathrm{I}_{R}\right)$, the disk current $\left(\mathrm{I}_{\mathrm{D}}\right)$, and the $\mathrm{H}_{2} \mathrm{O}_{2}$ collection efficiency $(\mathrm{n}=0.4735)$, using Equation 1;

$$
\mathrm{N}=4 \mathrm{I}_{\mathrm{D}} /\left[\left(\mathrm{I}_{\mathrm{R}} / \mathrm{n}\right)+\mathrm{I}_{\mathrm{D}}\right]
$$

\section{Results and Discussion}

Scanning electron microscopy (SEM) and transmission electron microscopy (TEM).- The microstructure of the samples was characterized by SEM (Figure 1). Figure 1a highlights the three-dimensional structure of a fragment of $\mathrm{CN}_{\mathrm{x}}-1000$. A spheroidal micron-scale pore / void is observed at the bottom of the fragment. Large, flat, graphenelike areas of carbon are visible, some of which protrude out-of-plane. Holes in the sheets are also present, as are many edges. $\mathrm{CN}_{\mathrm{x}}-1000$ and $\mathrm{CN}_{\mathrm{x}}-1400$ both have almost idential structure (Figures $1 \mathrm{~b}, 1 \mathrm{c}$ ); an interconnected, highly porous, three dimensional carbon framework with micron-scale macropores separated by thin carbon walls. The unique structure prevents restacking of the graphene-like sheets and subsequent loss of surface area. Restacking generally restricts the surface area of commercially available graphene powders to around $600 \mathrm{~m}^{2} / \mathrm{g}$. The large pores in this carbon foam are expected to aid mass transfer of reactants and products through the electrocatalyst layer. TEM images (Figures 1d, 1e) show higher magnification images at the edge of the graphene-like sheet, revealing a multilayered structure, and suggesting that the large sheets are essentially fewlayer nitrogen-doped graphene, albeit without the highly crystalline chemical structure.

BET surface area and pore size distribution.-The specific surface area and average pore size were calculated using the BET method, based on nitrogen adsorption/desorption isotherms. $\mathrm{CN}_{\mathrm{x}}-1000$ has a surface area of $705 \mathrm{~m}^{2} / \mathrm{g}$, and $\mathrm{CN}_{\mathrm{x}}-1400$ has a very similar value of $700 \mathrm{~m}^{2} / \mathrm{g}$. The average pore size of $\mathrm{CN}_{\mathrm{x}}-1000$ is $2.0 \mathrm{~nm}$, whilst $\mathrm{CN}_{\mathrm{x}}-1400$ has a slightly higher value of $2.5 \mathrm{~nm}$. This suggests that graphitization of this material slightly increases pore size, but does not have a large impact on the overall microstructure. This is important in the interpretation of the electrochemical results, since changes in microstructure due to heat-treatment can be discounted in this case. The theoretical maximum surface area of single-layer graphene is $2630 \mathrm{~m}^{2} / \mathrm{g}$. Dividing that value by the surface area of our samples gives a rough estimate of the number of layers, namely 3.7 in this case. This is consistent with AFM results previously reported by our group on similar samples. ${ }^{31}$ Figure 2 shows the pore size distribution; $\mathrm{CN}_{\mathrm{x}}-1000$ has a majority of pore sizes smaller than $5 \mathrm{~nm}$ in radius, whilst they are slightly bigger in the graphitized $\mathrm{CN}_{\mathrm{x}}-1400$ sample.

Inductively charged plasma (ICP).- The aim of this work is to investigate the ORR in metal-free nitrogen-doped carbon. Therefore, it is imperative that the presence of iron in the samples be ruled out. The sensitivity of e.g. XPS is insufficient to detect low concentrations 


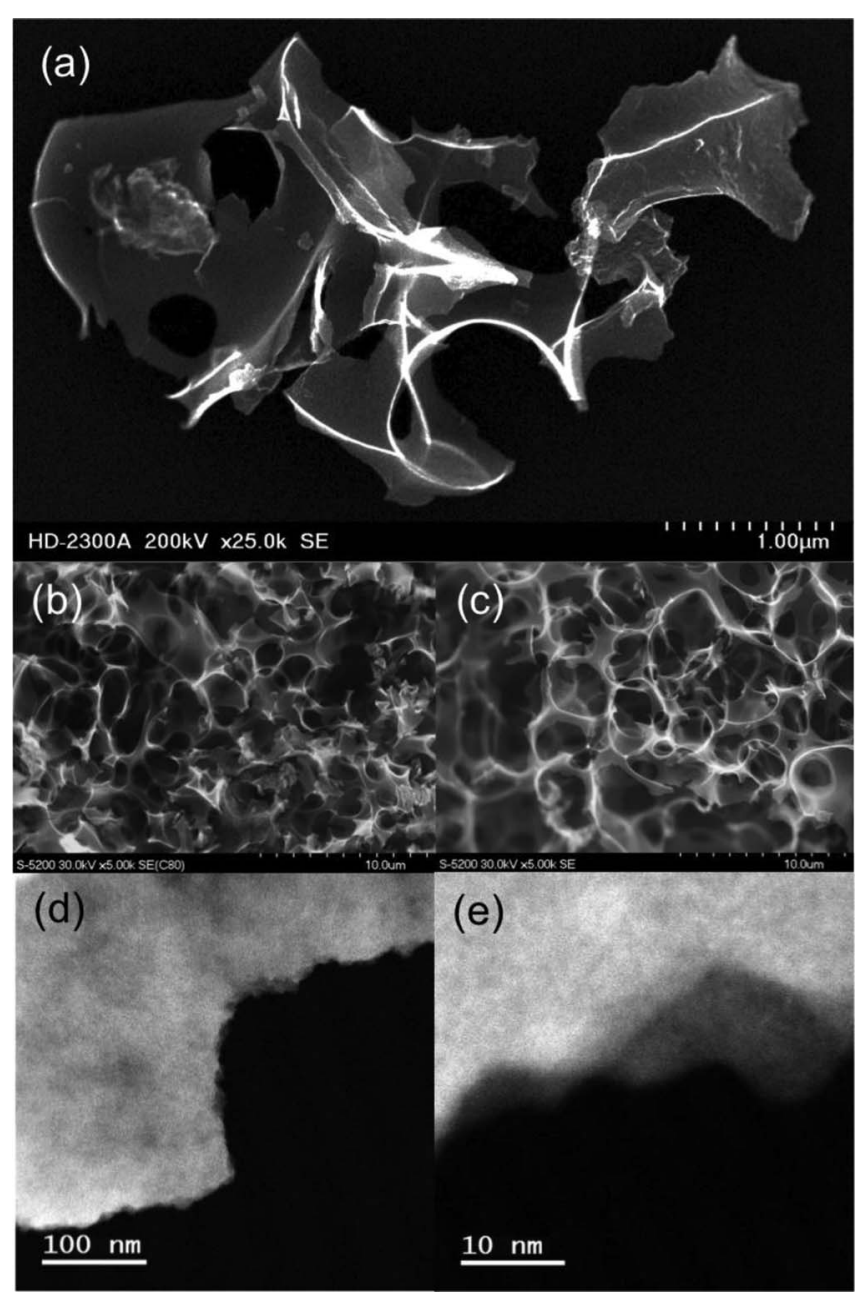

Figure 1. SEM images of (a,b) $\mathrm{CN}_{\mathrm{x}}-1000$, and (c) $\mathrm{CN}_{\mathrm{x}}-1400$. (d,e) TEM images of $\mathrm{CN}_{\mathrm{X}}-1400$.

of metallic elements $(<1$ at $\%)$. However low concentration metal inclusions still have a large impact on catalytic activity. ICP is very sensitive to metal cations, and therefore this technique was used. 4.2 $\mathrm{mg} \mathrm{GF} \mathrm{N}_{\mathrm{N}}$ was mixed with $20 \mathrm{ml}$ of concentrated $\mathrm{HCl}$ overnight. $3 \mathrm{ml}$ of the resulting solution was made up to $30 \mathrm{ml}$ with deionized water, and this was analyzed. The resulting concentration of $\mathrm{Fe}^{+}$ions was below the detection limit of the machine (1 ppb), confirming that the iron content in $\mathrm{GF}_{\mathrm{N}}$ is negligible. Other electrochemically active trace impurities such as Ni or Co may be contained e.g. in the sodium metal, however these are generally accepted to be less active than iron, and less abundant.

X-ray photoelectron spectroscopy (XPS).-X-ray photoelectron spectroscopy (XPS) was performed for elemental analysis (Figure 3 ). The wide-scan spectrum (Figure $3 \mathrm{a}$ ) shows a strong $\mathrm{C} 1 \mathrm{~s}$ signal at $284.5 \mathrm{eV}$; a weak N 1s signal at $\sim 400 \mathrm{eV}$; and a small $\mathrm{O} 1 \mathrm{~s}$ signal at $\sim 532 \mathrm{eV}$ for both samples. The oxygen content is slightly reduced from 9.1 at\% $\left(\mathrm{CN}_{\mathrm{x}}-1000\right)$ to 8.5 at\% after graphitization $\left(\mathrm{CN}_{\mathrm{x}}-1400\right)$. The nitrogen content is decreased from 1.3 at $\%$ for $\mathrm{CN}_{\mathrm{x}}-1000$, to 0.65 at $\%$ for $\mathrm{CN}_{\mathrm{x}}-1400$. High temperature heat-treatment is therefore shown to decrease the amount of oxygen and nitrogen in the samples, as expected. Carbonyl bonds $(\mathrm{C}=\mathrm{O}, 532.6 \mathrm{eV})$ are the major component in the $\mathrm{O} 1 \mathrm{~s}$ signal for both samples.

The $\mathrm{C}$ 1s spectra are shown in Figures $3 \mathrm{~b}$ and $3 \mathrm{~d}$, centered at $284.5 \mathrm{eV}$. The $\mathrm{N} 1 \mathrm{~s}$ spectra (Figures $3 \mathrm{~d}, 3 \mathrm{e}$ ) are deconvoluted into five peaks; (1) amine functional groups at $\sim 401.8 \mathrm{eV}$; (2) graphitic / tertiary nitrogen at $\sim 400.8 \mathrm{eV}$; (3) pyrrolic nitrogen at $\sim 399.8 \mathrm{eV}$; (4)

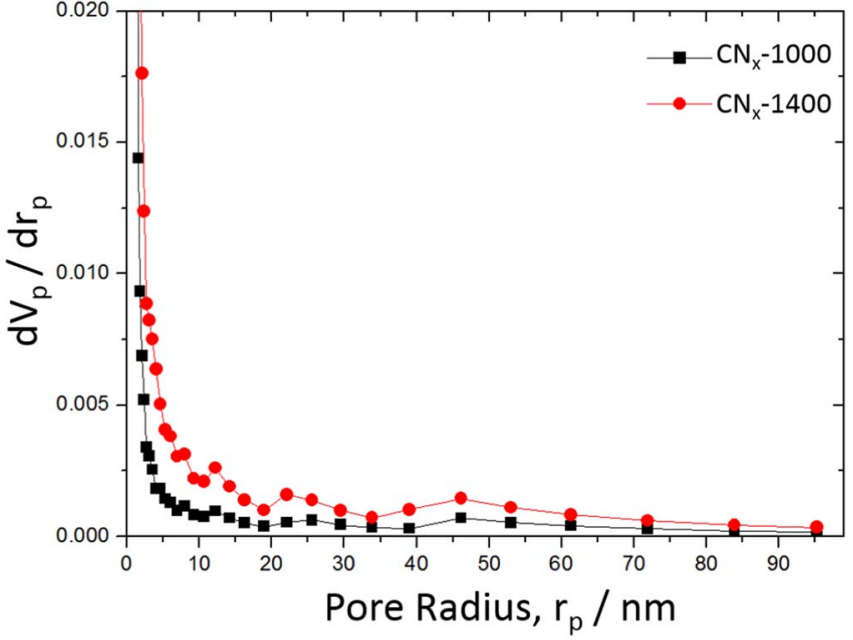

Figure 2. Pore size distributions for $\mathrm{CN}_{\mathrm{X}}-1000$ and $\mathrm{CN}_{\mathrm{X}}-1400$.

pyridinic nitrogen at $\sim 398.9 \mathrm{eV}$; and a small shoulder (5) at $\sim 397.8$ $\mathrm{eV}$ possibly corresponding to imine groups. ${ }^{41}$ The main difference between the two samples is that the proportion of tertiary (graphitic) nitrogen relative to pyridinic nitrogen significantly increases after graphitization. Edge-based pyridinic nitrogen has only two bonds and is removed more easily by heat-treatment than graphitic nitrogen with three bonds in the basal plane. Thus, tertiary nitrogen is the main chemical state in $\mathrm{CN}_{\mathrm{x}}-1400$, whilst an approximately equal mix of tertiary and pyridinic nitrogen is present in $\mathrm{CN}_{\mathrm{x}}-1000$.

Cyclic Voltammetry $(\boldsymbol{C V})$. - $\mathrm{CV}$ measurements were performed in $\mathrm{N}_{2}$ - and $\mathrm{O}_{2}$-saturated $0.1 \mathrm{M} \mathrm{HClO}_{4}$ solution (Figure 4). The double layer capacitance of $\mathrm{CN}_{\mathrm{x}}-1000$ is higher than $\mathrm{CN}_{\mathrm{x}}-1400$, despite the similar surface area. Therefore, the decrease in double layer capacitance may be attributed to the larger pores in $\mathrm{CN}_{\mathrm{x}}-1400 .{ }^{42}$ Under $\mathrm{N}_{2}$ flow, the CV curves are largely featureless, which is typical of carbon-based materials. Under $\mathrm{O}_{2}$ flow, the ORR activity of $\mathrm{CN}_{\mathrm{x}}-$ 1400 is slightly improved compared with $\mathrm{CN}_{\mathrm{x}}-1000$.

Rotating ring-disk electrode voltammetry (RRDE).- $\mathrm{RRDE}$ measurements were performed in $\mathrm{O}_{2}$-saturated $0.1 \mathrm{M} \mathrm{HClO}_{4}$. The mass activity of $\mathrm{CN}_{\mathrm{x}}-1000$ (Fig. 5a) is $0.46 \mathrm{~A} / \mathrm{g}$ at $0.6 \mathrm{~V}_{\mathrm{RHE}} \cdot \mathrm{CN}_{\mathrm{x}}-1000$ does not show any mass diffusion limited current, however the maximum current density is $-3.4 \mathrm{~mA} / \mathrm{cm}^{2}$ at $2500 \mathrm{rpm}$. The onset potential is around $0.8 \mathrm{~V}_{\mathrm{RHE}}$ for $\mathrm{CN}_{\mathrm{x}}-1000$, calculated from the $1^{\text {st }}$ derivative of the current density (inset). This is an unusual method for the determination of onset potential, but provides an accurate and consistent value compared with simply estimating the point where an arbitrary current density is reached. Whilst this is low compared with $\mathrm{Pt}$ (e.g. $1.08 \mathrm{~V}_{\mathrm{RHE}}$ ), it must be noted that this is a completely metal-free electrocatalyst. The electron transfer number ranges from around 2.5 at low current densities, to 3.3 at higher current density.

After graphitization, $\mathrm{CN}_{\mathrm{x}}-1400$ (Fig. 5b) has a mass activity of 2.79 $\mathrm{A} / \mathrm{g}$ at $0.6 \mathrm{~V}_{\mathrm{RHE}}$, which is six times higher than that of $\mathrm{CN}_{\mathrm{x}}-1000$. A mass diffusion limited current is not quite reached, but saturation does start to occur $\left(-4.0 \mathrm{~mA} / \mathrm{cm}^{2}\right.$ at $\left.2500 \mathrm{rpm}\right)$. The gradients of the slopes are greater than for $\mathrm{CN}_{\mathrm{x}}-1000$, indicating lower resistance due to the graphitization step. The onset potential is $\sim 0.85 \mathrm{~V}_{\mathrm{RHE}}$ (inset). This is higher than $\mathrm{CN}_{\mathrm{x}}-1000$, and compares favorably even with many $\mathrm{Fe} / \mathrm{N} / \mathrm{C}$-based electrocatalysts, despite the metal-free nature of this sample. It also indicates a significant proportion of oxygen reduction via the 4-electron ORR pathway, since the theoretical overpotential for 2-electron ORR is much lower, at $0.695 \mathrm{~V}_{\mathrm{RHE}}$. The electron transfer number varies from $\sim 3.0$ to 3.6 , also indicating that the graphitization step results in an increase in the proportion of 4-electron transfer. 

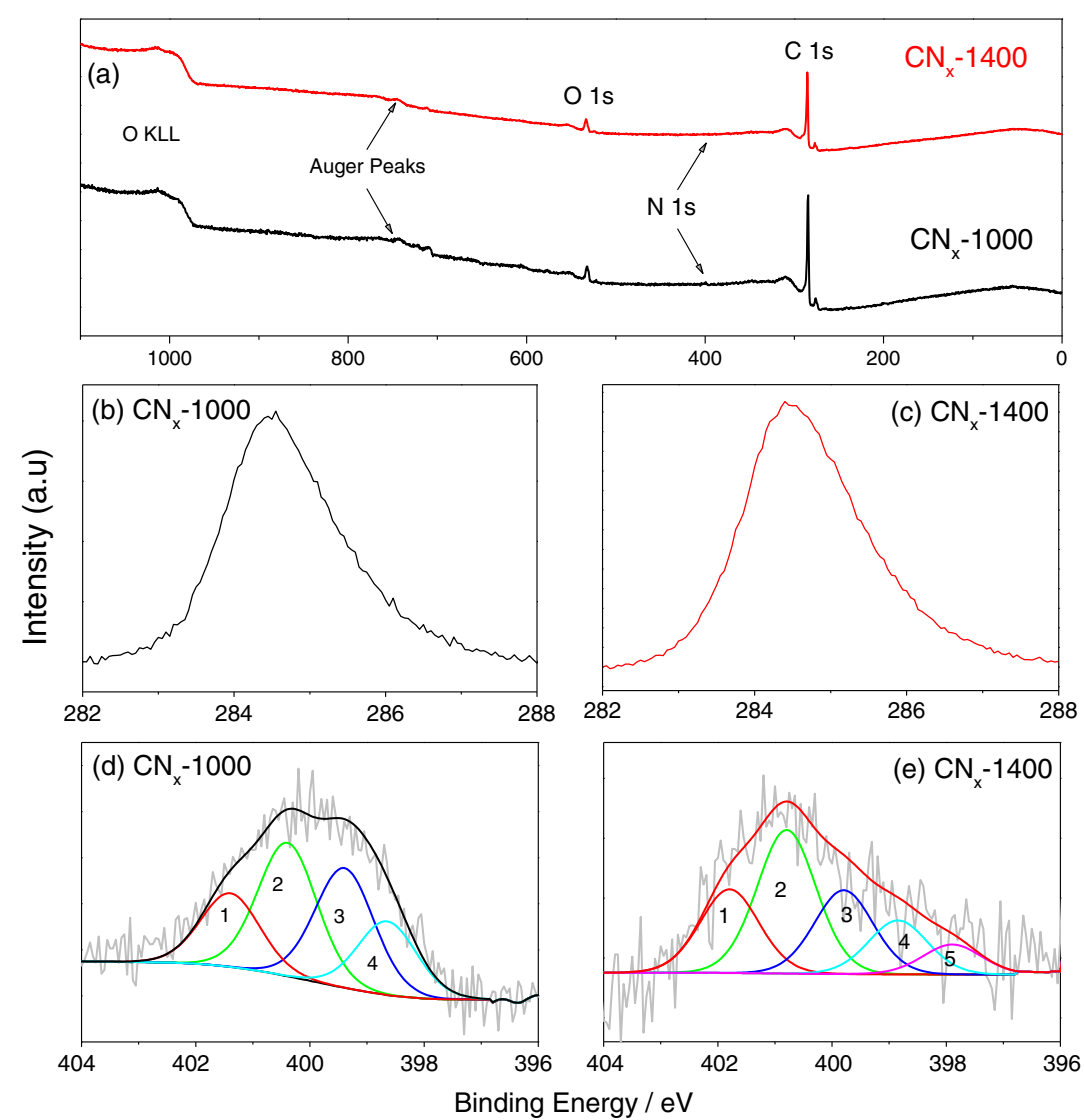

Figure 3. (a) XPS wide scan spectra. C 1s spectra for (b) $\mathrm{CN}_{\mathrm{X}}-1000$ and (c) $\mathrm{CN}_{\mathrm{X}}-1400 . \mathrm{N}$ 1s spectra for (d) $\mathrm{CN}_{\mathrm{X}}-1000$ and (e) $\mathrm{CN}_{\mathrm{X}}-1400$.
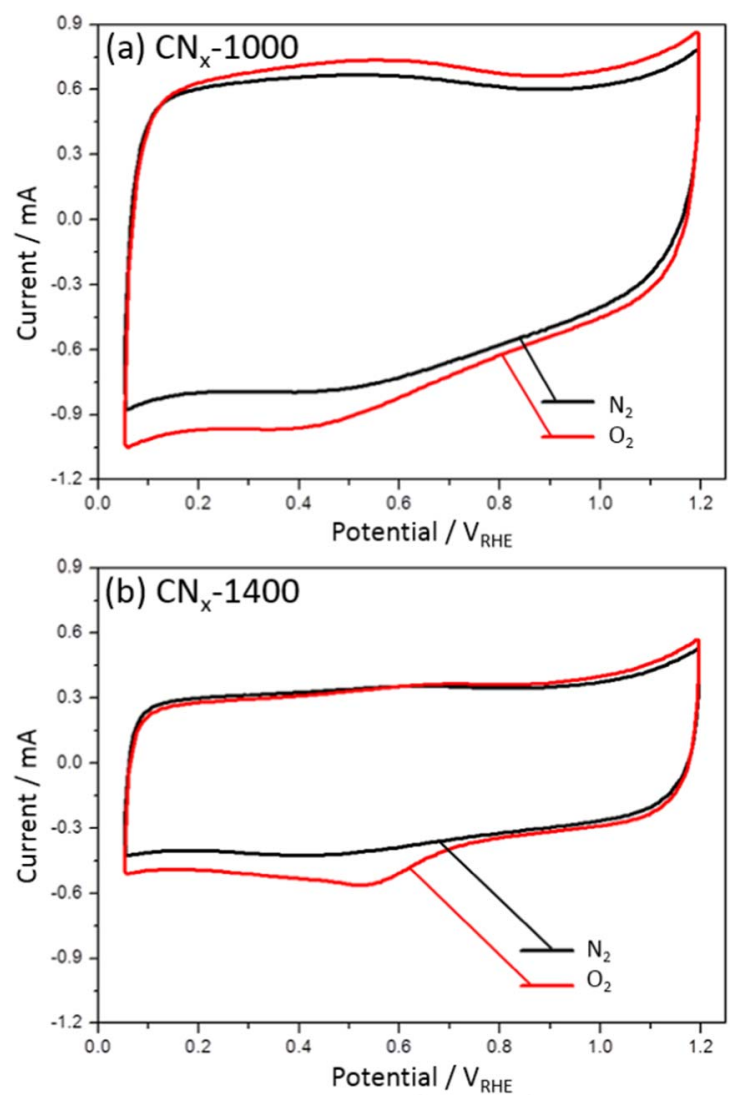

Figure 4. Cyclic voltammograms of (a) $\mathrm{CN}_{\mathrm{x}}-1000$ and (b) $\mathrm{CN}_{\mathrm{x}}-1400$, on a glassy carbon-disk / Pt-ring electrode in $\mathrm{N}_{2}$ - and $\mathrm{O}_{2}$-saturated $0.1 \mathrm{M} \mathrm{HClO}_{4}$ at $25^{\circ} \mathrm{C}$, with a scan rate of $50 \mathrm{mV} / \mathrm{s}$.

\section{Discussion}

Whilst it is widely accepted that iron-coordinated nitrogen active sites are active for the ORR with a 4-electron pathway, there is still debate about whether metal-free nitrogen-doped carbon can catalyze a 4-electron ORR pathway in acid medium. It is often assumed that such materials will mainly catalyze oxygen reduction in a 2-electron pathway to form hydrogen peroxide. Here however, we observe a majority 4-electron pathway, despite the proven metal-free nature of the samples. In addition, we observe high onset potential and current density compared with other "metal-free" electrocatalyst systems reported in the literature. ${ }^{32-34}$ The mass activities reported here even compare well with many reported Fe/N/C-based electrocatalysts, ${ }^{11}$ although are clearly some way off competing with the best reported values. $^{6,7}$ It is also interesting to note that for these Fe-free carbon foam electrocatalysts, the activity is much improved by graphitization at high temperature (in this case, $1400^{\circ} \mathrm{C}$ ). This is in contrast to the case of the transition-metal containing electrocatalysts, in which the ORR activity peaks at e.g. 600 to $800^{\circ} \mathrm{C}$ and then is drastically reduced at higher temperature. This is further evidence of the fundamentally different nature of metal-free versus metal-containing catalysts for this reaction.

The reasons for the relatively high electrochemical activity achieved in our work are probably threefold. Firstly, the surface area is large, at $700 \mathrm{~m}^{2} / \mathrm{g}$. This increases the triple phase boundary, thereby increasing the current density. Generally, much lower surface areas are reported for metal-free studies in the literature. ${ }^{34}$ Additionally, the pore-size is very large compared with e.g. mesoporous carbons, resulting in increased mass transport, also a major factor in catalyst performance. ${ }^{43}$ However, the higher activity of $\mathrm{CN}_{\mathrm{x}}-1400$ compared with $\mathrm{CN}_{\mathrm{x}}-1000$ cannot be explained by surface area, as they are both almost identical. The second possible factor leading to high electrochemical activity is therefore conductivity. Graphitization increases conductivity in carbon, ${ }^{44-46}$ in this case resulting in improved electron transport through the electrocatalyst layer. Evidence for this is in 

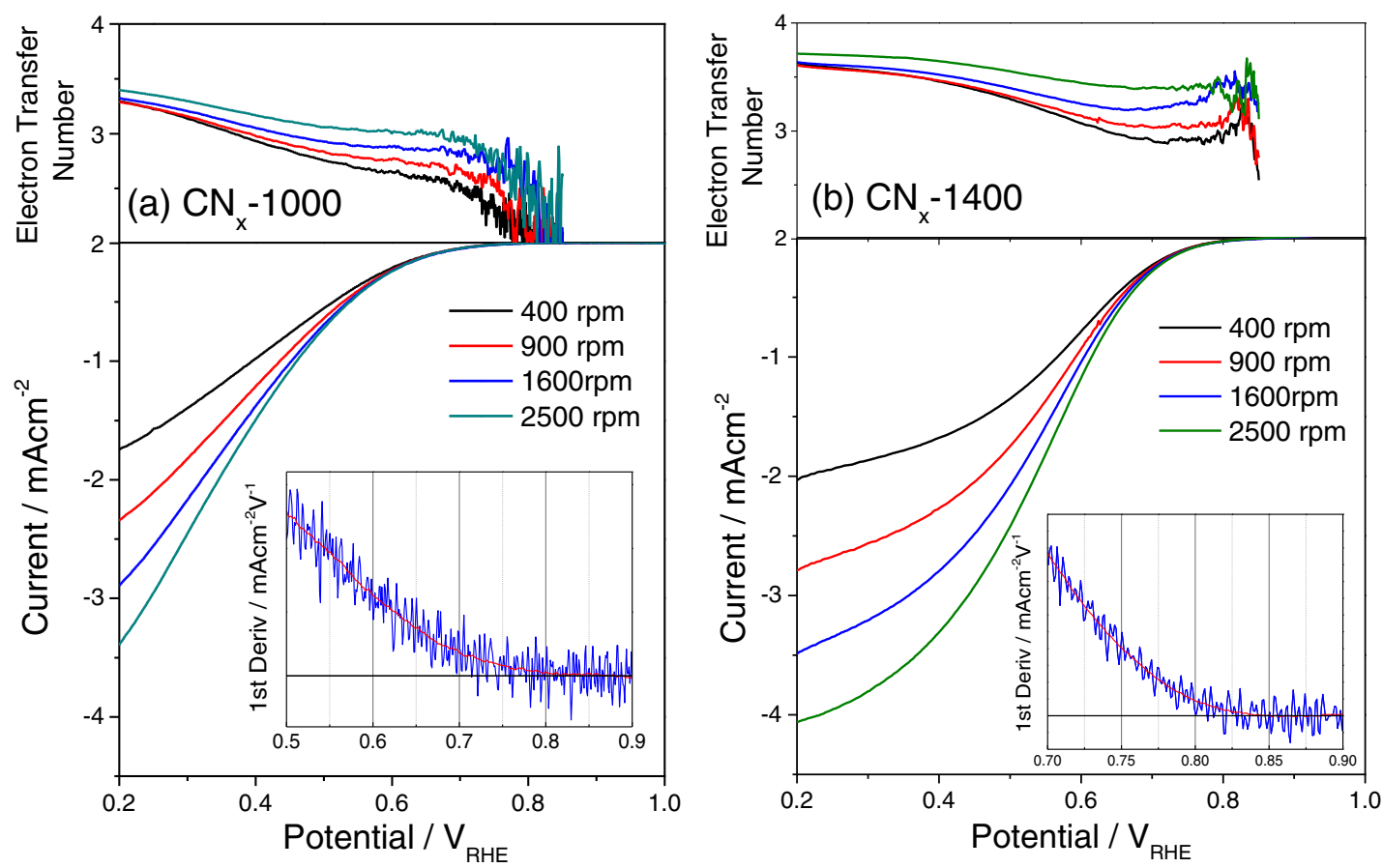

Figure 5. Rotating disk current density; electron transfer number; and $1^{\text {st }}$ derivative of the onset region for: (a) $\mathrm{CN}_{\mathrm{x}}-1000$ and (b) $\mathrm{CN}_{\mathrm{x}}-1400$, in $\mathrm{O}_{2}$-saturated 0.1 $\mathrm{HClO}_{4}$ on a glassy carbon-disk Pt-ring electrode at $25^{\circ} \mathrm{C}$, with a scan rate of $10 \mathrm{mV} / \mathrm{s}$.

the steeper gradient of the LSV curves after graphitization, indicating lower resistance and reduced $\mathrm{iR}$ losses. The third possibility is that $\mathrm{CN}_{\mathrm{x}}-1400$ has a greater proportion of 4-electron pathway active sites, namely tertiary nitrogen sites. There is a significantly higher proportion of tertiary to pyridinic nitrogen in $\mathrm{CN}_{\mathrm{x}}-1400$, as evidenced by XPS measurements. This nitrogen configuration has been suggested to be active for the ORR in several theoretical models. ${ }^{18-20,47,48}$ Our results provide some experimental verification of these models. It should be noted that evidence of a 4-electron pathway in metal-free systems does not necessarily mean that such metal-free active sites are responsible for the ORR activity of Fe-containing electrocatalyst systems. The Fe-coordinated pyridinic nitrogen active site is still likely much more active than the Fe-free system. However, such metal-free tertiary nitrogen active sites may contribute significantly to the overall ORR current density in Fe/N/C-based non-precious electrocatalyst systems, especially at high current density $\left(<0.6 \mathrm{~V}_{\mathrm{RHE}}\right)$.

\section{Conclusions}

Nitrogen-doped carbon foams with large surface area $\left(700 \mathrm{~m}^{2} / \mathrm{g}\right)$ were synthesized and pyrolyzed at different temperatures. These were applied as metal-free electrocatalysts for the ORR in acid, in order to shed light on the active site in non-PGM electrocatalysts. SEM images revealed the highly porous nature of the material. The proportion of tertiary bonded nitrogen increased significantly after graphitizaion at $1400^{\circ} \mathrm{C}$. Heat treatment also significantly improved the electrochemical activity. An onset potential of $0.85 \mathrm{~V}_{\mathrm{RHE}}$, a mass activity of $2.79 \mathrm{~A} / \mathrm{g}$ at $0.6 \mathrm{~V}_{\mathrm{RHE}}$, and a current density of $-4 \mathrm{~mA} / \mathrm{cm}^{2}$ were recorded, and the maximum electron transfer number was 3.6. These results confirm that a 4-electron ORR pathway is indeed possible in nitrogen-doped carbon in the absence of $\mathrm{Fe}$ atoms. The increase in electron transfer number with the proportion of tertiary nitrogen suggests that this arrangement of nitrogen and carbon is responsible for the 4-electron oxygen reduction reaction in acid. Given the above findings, we are currently focusing on increasing the surface area, conductivity, and nitrogen content of our nitrogen-doped carbon foams in order to further improve the electrochemical activity of this unique material.

\section{Acknowledgments}

The authors gratefully acknowledge the support of the International Institute for Carbon Neutral Energy Research (WPI-I2CNER), sponsored by the World Premier International Research Center Initiative (WPI), MEXT, Japan; and the International Research Center for Hydrogen Energy, Kyushu University. This work was supported by JSPS KAKENHI Grant-in-Aid for Encouragement of Young Scientists (B), grant Number 15K17898; and a Royal Society of Chemistry Mobility Fellowship.

\section{References}

1. H. Jahnke, M. Schönborn, and G. Zimmermann, Top. Curr. Chem., 61, 133 (1976).

2. V. S. Bagotzky, M. R. Tarasevich, K. A. Radyushkina, O. A. Levina, and S. I. Andrusyova, J. Catal., 2, 8 (1973).

3. S. Gupta, D. Tryk, I. Bae, W. Aldred, and E. Yeager, J. Appl. Electrochem., 19, 19 (1989).

4. H. Wang, R. Côté, G. Faubert, D. Guay, and J. P. Dodelet, J. Phys. Chem. B, 103, 2042 (1999)

5. F. Jaouen, S. Marcotte, J.-P. Dodelet, and G. Lindbergh, J. Phys. Chem. B, 107, 1376 (2003).

6. F. Jaouen et al., Energy Environ. Sci., 4, 114 (2011)

7. M. H. Robson, K. Artyushkova, W. Patterson, P. Atanassov, and M. R. Hibbs, Electrocatalysis (2013)

8. Y. Nabae et al., ECS Trans., 25, 463 (2009).

9. H. A. Gasteiger, S. S. Kocha, B. Sompalli, and F. T. Wagner, Appl. Catal. B Environ., 56, 9 (2005).

10. S. Stariha, A. Serov, B. Halevi, and P. Atanassov, in 2014 ECS and SMEQ Joint International Meeting (October 5-9, 2014), Ecs (2014).

11. J.-P. Dodelet, in Electrocatalysis in Fuel Cells, Lecture Notes in Energy. D. Shao, D. MinHiggins, and Z. Chen, Editors, vol. 9, p. 271, Springer London, London (2013).

12. A. Zitolo et al., Nat. Mater, 14, 937 (2015).

13. Y. Tison et al., ACS Nano (2015).

14. K. Wiesener, Electrochim. Acta, 31, 1073 (1986)

15. S. Maldonado and K. J. Stevenson, J. Phys. Chem. B, 108, 11375 (2004).

16. P. Matter, L. Zhang, and U. Ozkan, J. Catal., 239, 83 (2006).

17. N. P. Subramanian et al., J. Power Sources, 188, 38 (2009).

18. T. Ikeda et al., J. Phys. Chem. C, 112, 14706 (2008).

19. H. Niwa et al., J. Power Sources, 187, 93 (2009).

20. F. Vallejos-Burgos et al., Fuel, 99, 106 (2012).

21. J. A. Menéndez, J. Phillips, B. Xia, and L. R. Radovic, Langmuir, 12, 4404 (1996)

22. L. Qu, Y. Liu, J.-B. Baek, and L. Dai, ACS Nano, 4, 1321 (2010).

23. K. Gong, F. Du, Z. Xia, M. Durstock, and L. Dai, Science, 323, 760 (2009). 
24. D. Yu, Q. Zhang, and L. Dai, J. Am. Chem. Soc., 132, 15127 (2010).

25. D. Geng et al., Energy Environ. Sci., 4, 760 (2011).

26. F. G. Lepri et al., Talanta, 81, 980 (2010).

27. S. M. Lyth and S. R. Silva, Appl. Phys. Lett., 90, 173124 (2007).

28. S. M. Lyth et al., J. Nanosci. Nanotechnol., 12, 4887 (2012).

29. S. M. Lyth et al., J. Electrochem. Soc., 158, B194 (2011).

30. S. M. Lyth et al., e-Journal Surf. Sci. Nanotechnol., 10, 29 (2012).

31. J. Liu, D. Takeshi, D. Orejon, K. Sasaki, and S. M. Lyth, J. Electrochem. Soc., 161, F544 (2014).

32. T. Iwazaki, R. Obinata, W. Sugimoto, and Y. Takasu, Electrochem. commun., 11, 376 (2009).

33. T. Iwazaki, H. Yang, R. Obinata, W. Sugimoto, and Y. Takasu, J. Power Sources, 195 5840 (2010).

34. M. Chokai et al., J. Power Sources, 195, 5947 (2010).

35. C. V. Rao, C. R. Cabrera, and Y. Ishikawa, J. Phys. Chem. Lett., 1, 2622 (2010).
36. X. Wang et al, Chem. Mater, 22, 2178 (2010).

37. Z. Lin et al., Phys. Chem. Chem. Phys., 14, 3381 (2012).

38. O.-H. Kim et al., Sci. Rep., 5, 8376 (2015).

39. M. Shao, Q. Chang, J.-P. Dodelet, and R. Chenitz, Chem. Rev., 116, 3594 (2016).

40. N. Daems, X. Sheng, I. F. J. Vankelecom, and P. P. Pescarmona, J. Mater. Chem. A, 2, 4085 (2014).

41. K. L. Tan, B. T. G. Tan, E. T. Kang, and K. G. Neoh, J. Mater. Sci., 27, 4056 (1992).

42. P. Simon and A. Burke, Electrochem. Soc. Interface (2008).

43. J. Park, Y. Nabae, T. Hayakawa, and M. Kakimoto, (2014).

44. J. Liu, K. Sasaki, and S. M. Lyth, ECS Trans., 64, 1161 (2014)

45. M. Sevilla and A. B. Fuertes, Carbon N. Y., 44, 468 (2006).

46. X. Zhao et al., Electrochim. Acta, 97, 33 (2013).

47. L. R. Radovic, J. Am. Chem. Soc., 131, 17166 (2009).

48. M. Kobayashi et al., Electrochim. Acta, 74, 254 (2012). 